\title{
Multiple symptoms of total ozone recovery inside the Antarctic vortex during austral spring
}

Andrea Pazmiño et al.

Correspondence to: Andrea Pazmiño (andrea.pazmino@latmos.ipsl.fr)

The copyright of individual parts of the supplement might differ from the CC BY 4.0 License. 

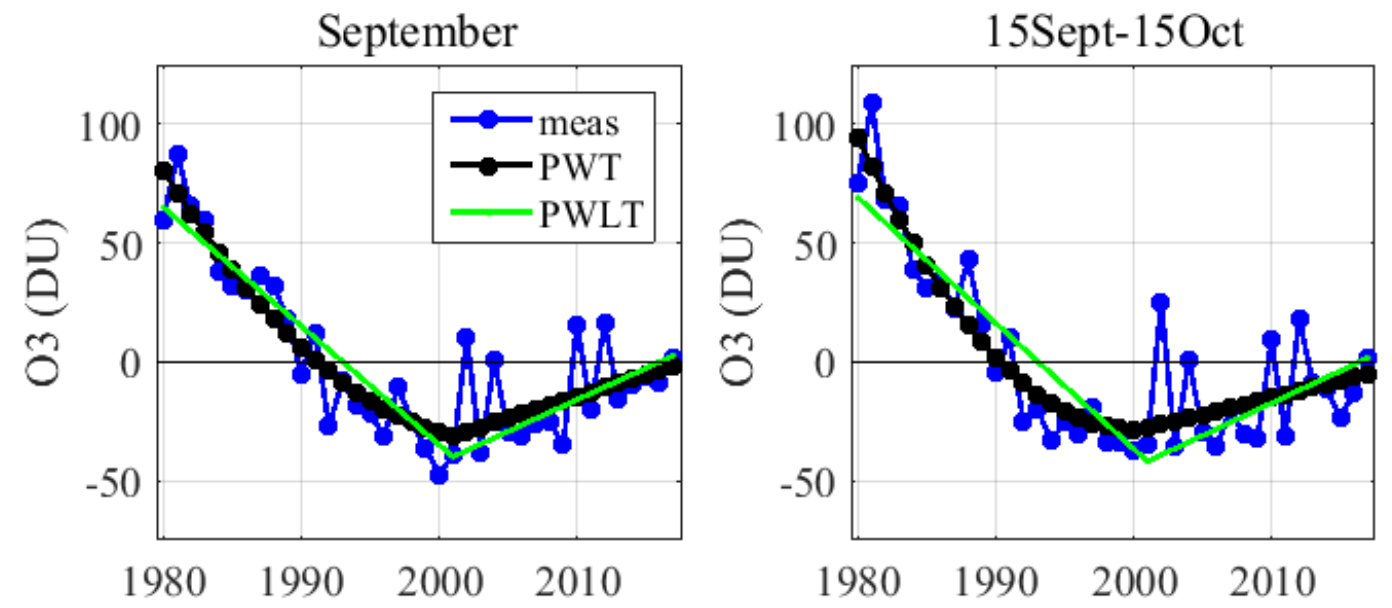

Figure S1: Deseasonalised average ozone inside the vortex of MSR-2 series for September (left panel) and 15Sept-15Oct period (right panel) using 400 K-600 K classification range. Regressed trends obtained by MLR analysis using PWT and PWLT as proxies are also shown.
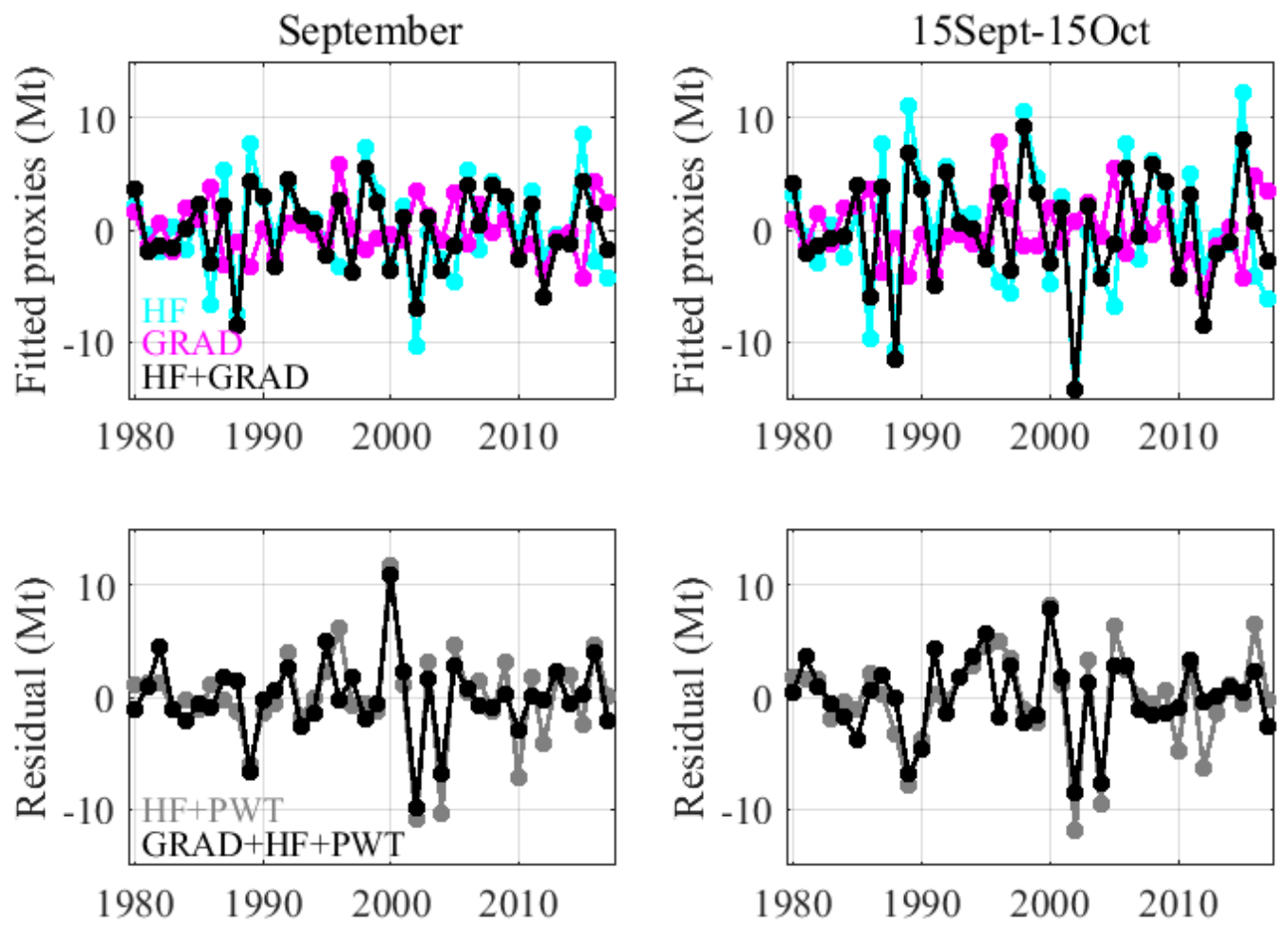

Figure S2: Fitted Heat Flux - HF, gradient - GRAD and the combination of both HF+GRAD proxies for September and 15Sept-15Oct periods (top panels) using MLR analysis on OMD. Corresponding residuals (in Mt) with and without contribution of GRAD proxy are shown in bottom panels. 

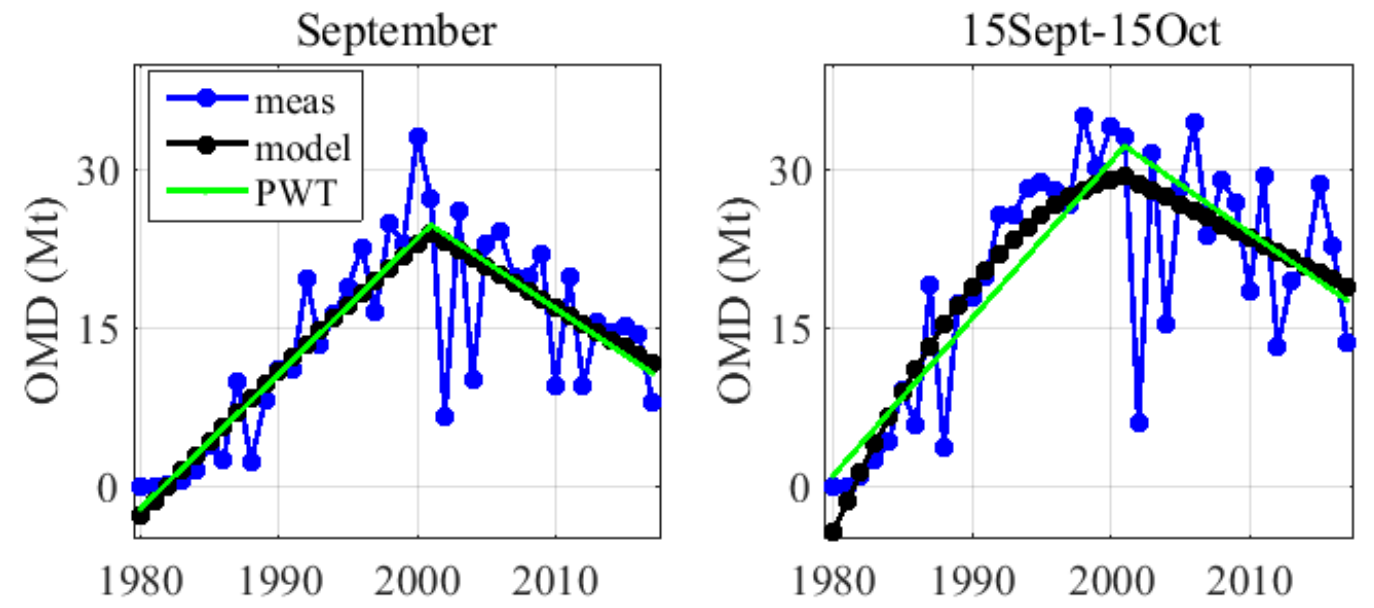

Figure S3: Deseasonalised mean OMD of MSR-2 series for September (left panel) and 15Sept-15Oct period (right panel). Regressed trends obtained by MLR analysis using PWT and PWLT as proxies are also shown. 